\title{
Developmental Trend of Insurance Actuarial System and the Influences on Modern Financial Industry
}

\author{
Su Wei \\ Qinghai University of Finance and Economics College, Qinghai, Xining 810001, China. \\ vzxfrb@163.com
}

\begin{abstract}
This paper analyzes the developmental trend of insurance actuarial system and the related influences on modern financial industry. The basic principle of insurance is to many premium to the underwriter, policy-holder, when the risk occurred shall be borne by the insurer. By paying a small amount of this mechanism make policy-holder and fixed premium, it will be a lot of uncertain losses to the insurance company or underwriter; Insurers use premium income on the one hand, ensure the normal conduct of compensation, while on the other hand, through the analysis and calculation to the reasonable allocate funds, improve the investment benefit of insurance funds, that eventually make policy-holder and underwriter gains. Our paper analyzes the basic principles of the insurance actuarial system and discusses the corresponding influences on the modern financial system.
\end{abstract}

Keywords: Modern financial, industry; actuarial system; trend of insurance; development.

\section{Introduction}

In social life, human will often face many risks, from the overall risk of the consistency and stability, and from a local point of view, risk and has the characteristics of the sudden, uncertainty and basic unpredictability, but overall the loss caused by the occurrence of the risk and risk is to follow certain distribution. This is the inherent logic of social insurance. In this understanding, many countries in the economic, social and other fields appeared a huge change. In the United States, gradually no longer applicable to industrial accident compensation fault liability of tort law and inductrial injury insurance "began to be introduced. And it is in response to the industrial accident, in the process of the scientific management began to rise in the enterprise until now still is an important rule [1-2].

Actuarial standards are to clarify the effect of the actuaries' duties, constraint actuaries' behavior, to inform customers and other users of their rights and to protect the public interest and so on. In developed countries, an actuarial standard are the guide of actuaries deal with the general problems as well as integrity, independence and high quality service commitment, therefore, the stand or fall of a country or a region actuarial development status that can be reflected from the perfect degree of the actuarial standards. At present, the insurance company involved in pricing of commercial endowment insurance actuarial model mainly includes the market demand, while customer utility model, the ruin probability model, profit-oriented pricing model, etc.

Actuarial science originated from Britain, grew up in England, developed in the North America. Because actuarial science is a branch of basic applied mathematics, and originated in the premium calculation, therefore, mathematics, actuarial science is often referred to as the insurance or actuarial mathematics. Transnational flow of the financial insurance resources and the formation of the world insurance concern are more complex, the investment actuaries and actuaries' talent demand gap.

Insurance, as an effective way to deal with risk in commercial society, has been widely accepted by the world. In the process of basic modern insurance industry vigorous development, the method of scientific theory, as especially the accurate quantitative calculation, plays a very important role. Some important link in the insurance business, such as the design of the new risks, insurance rates and reserve calculation, the determination of points in coverage, pension and other social security plan, etc., all need by the basis of actuaries actuarial science principles to the analysis and processing. In this paper, to review the architecture of the system we will analyze in detail later [3]. 


\section{The Proposed Perspectives}

\subsection{Modern Financial System.}

Modern finance is a financial organization form and different financial allocations constitute the sum of the coupling relationship between the checked. Commercial finance, policy finance and financial cooperative constitute the main content of modern finance. New financial view based on the theory of the general three-dimensional financial architecture in the perspective of economic, social and the humanities, philosophy is the basic context of the financial system.

Compared with the traditional financial, modern finance in the financial structure and financial tools, financial function, the relationship between the economy and the great changes have taken place in many ways, such as, only from the general industry, the mediation, services and other traditional perspective to study the financial problem is difficult to summarize the outline of the modern finance. With a fresh perspective and, therefore, it is imperative to view the financial, financial reform is imperative, financial discipline research methods reform is imperative. This is not only practical workers, theoretical workers must deal with challenges is also foundation of financial management department to make scientific financial decision making [4].

Three-dimensional financial under the view of financial research methods is a three-dimensional financial architecture theory basis of the methodology of development and evolution, this research method compared with the traditional economics research method has following three characteristics. (1) From the point of discipline development history, that economics is a branch of political science, political science is an important part of the philosophy, was originally a total of three; Later, with the development of discipline, politics and economics gradually developed as an independent discipline, this separation is required, specialization institute is relative in the sense of separation. (2) The study of 3D financial architecture is based on the value judgment of finance research results, this is due to the traditionally based on the value judgment of the efficiency of research paradigm has been difficult to cover the whole content of modern finance. Modern finance is not only the efficiency of resource allocation problems and there is the question of social rationality in the process of configuration. (3) All walks of life to guide and standard, the development direction of each department and financial department as the core of modern economy, its development is agree with the essential requirement of scientific concept of development to the great extent, determines the implementation of the scientific outlook on development of water quality and the overall economic and social development (Fig. 1).

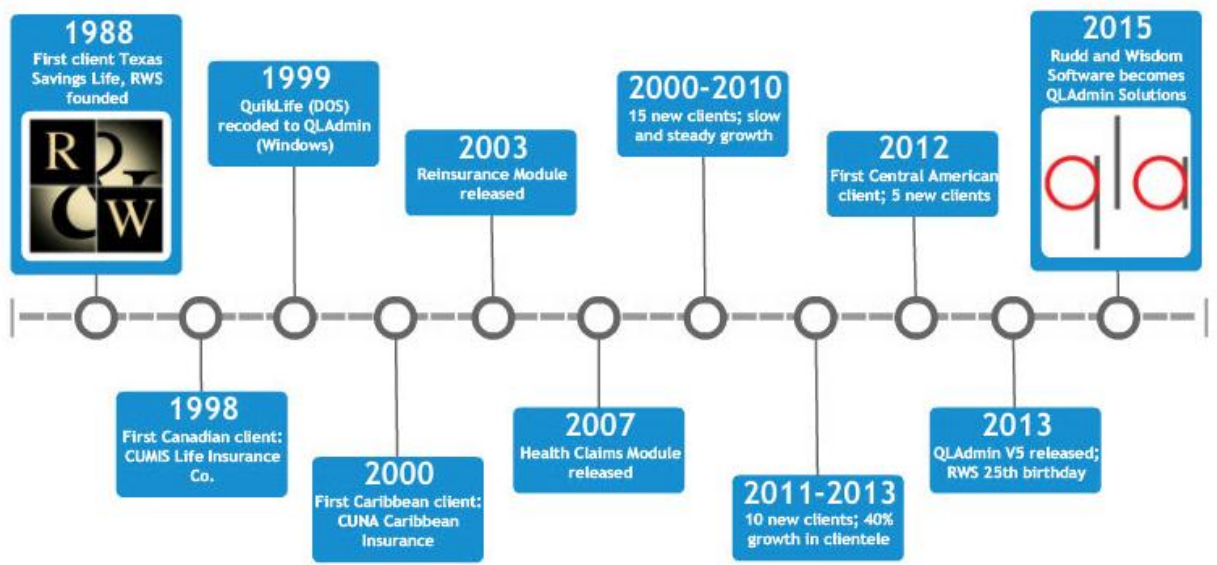

Fig. 1 The Developmental Paths of the Modern Financial System

\subsection{Insurance System.}

Banking system has the high debt management itself inherent instability and vulnerability of the characteristics of deposit insurance system is by creating incentive compatibility mechanism to promote the development of banking prudent, in the market participants to create a fair competition platform, with economies of general scale advantage solve the problem of asymmetric information, reduce the impulse of depositors to participate in or a deposit accounts, within the scope of insurance to protect depositors, increase public confidence in financial institutions, limit the spread of the bank's risk, stabilize the financial system, and promote growth. 
In addition to the absolute scale and relative position, when evaluating system risk, still need to consider the correlation between the risk if the business has good risk dispersion and complementarity between, even on a large scale it is still not enough to cause the overall risk of uncontrolled and turned into a systemic risk. From the research data as large insurance companies are often more fully than the commercial banks has the better and enhanced diversification.

The government as a provider of the public services, safeguard basic life, helps them realize the unemployed again obtain employment is one of the important social functions of government. To ensure the basic life good for the unemployed is the important path of developing and perfecting our country's unemployment insurance system, establish a social unemployment insurance system. Any insurance system establishment, financing is a primary key problems that raise the level of insurance coverage, security level, and many of other aspects. Savings accumulation or as a fully funded funds system, its main characteristic is laborer and unit of choose and employ persons from their income to the worker in the individual account pays a fixed number of contributions, by the specific institutions focus for investment, later to policyholders to pay premiums and investment returns, at the beginning of security commitments to policy-holder how much benefit associated with the insured amount.

\subsection{Principles of Actuarial Studies.}

Insurance economics is a branch of basic economics, using the principles of economics to the analysis, and the research about insurance problem in the field of a discipline. From the micro level, insurance economics individual, that the insurer, insurance broker, insurance regulators in the market of behavior decision-making, how to achieve the optimum utility under limited resources. From fig. 2, we demonstrate the architecture [5].

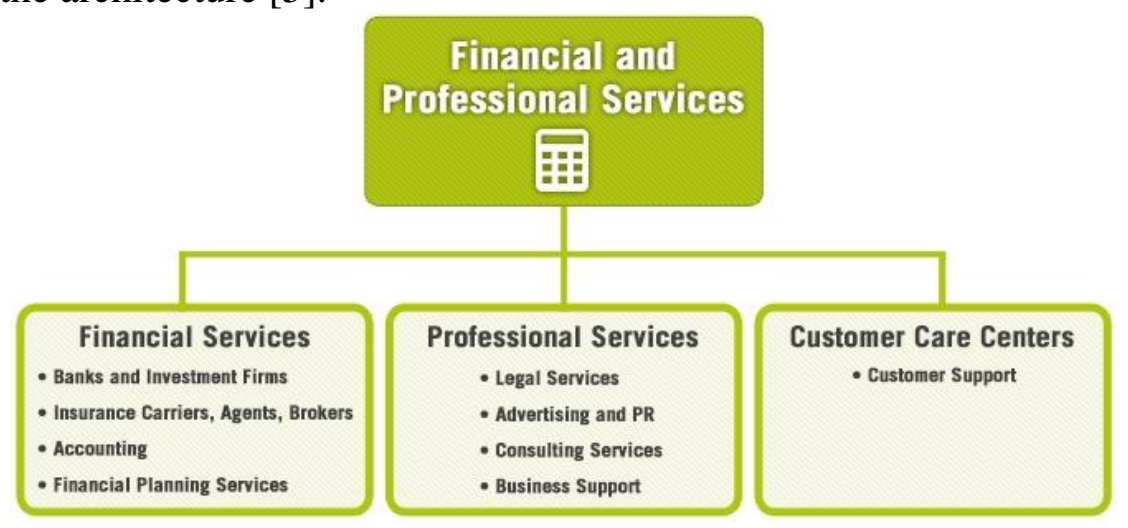

Fig. 2 The Principles of Actuarial Studies

It can be seen from the above analysis, the mathematical basis of pricing in actuarial science is pure mathematics, probability and the statistics, and pricing in the more insurance economics is based on financial mathematics, stochastic process that can be organized as follows.

- Insurance economics based on the premium market equilibrium calculation, while the optimal insurance premiums, etc., make full use of the principles of economics, such as supply and demand equilibrium principle, principle of utility maximization, and the theory of structure.

- Look from the mathematical basis, actuarial science focus on pure mathematics, probability and statistics, mathematical tools, and focuses on the application of insurance economics, random process, and financial markets combine closely mathematical tools.

- Insurance pricing in insurance economics and actuarial science differs in insurance pricing, pricing in the price of insurance of insurance economics decided to give full consideration to the role of the market, in the process of application of equilibrium price decision principle of economics. Policy, therefore, the price should be the risks and benefits of an equilibrium.

Financial pricing model, such as portfolio selection model, the capital asset pricing model, optimal securities investment theories, across the period of the capital asset pricing model, arbitrage pricing theory, option pricing theory, discount cash flow model and so on that plays an important role in the insurance pricing, and insurance products pricing in insurance economics important mathematical theories. After applying the capital asset pricing model to insurance can be found that equilibrium insurance prices reflect the constant risk in the insurance business. If there is no statistical correlation 
insurance risk and the financial market risk, then the equilibrium price of insurance is expected cost is determined the present value of the claim.

\subsection{Trend of Insurance Actuarial System.}

Non-life insurance actuarial development to today, as its function has permeated in every link of the insurance company's business, including the design of the insurance products and pricing, that various business reserves evaluation and extraction, assets and liabilities management, solvency calculation, reinsurance arrangement, risk management and general investment, etc. The appointed actuary system is an important characteristic of the non-life insurance actuarial abroad, the main responsible for the monitoring and assessment of the assets and liabilities and guarantee insurance company reported to the regulatory information is true and accurate.

Specify an actuary is the insurance company shall, in accordance with the insurance law and basic insurance companies' management regulations special actuaries must be employed. Specify the hiring and firing of actuaries must go through regulatory agencies, including the association of actuaries' recognition and approval, to ensure an objective fair, maximize the maintenance of the insured and the interests of the shareholders. This system can not only guarantee the authenticity and rationality of the data, but also from the perspective of actuaries' professional comprehensive measure.

Specify an actuary can monitor the financial situation of the company, as capital adequacy, and so on and so forth, and not just at the end of the financial year one-time evaluation on company balance sheets. Specified actuaries to insurance company's financial situation is the major function of the real rationality of independent and objective evaluation, evaluation of internal control and process of insurance company, and independent advice is provided for evaluation of insurance liabilities.

\section{Conclusion}

This paper analyzes the developmental trend of insurance actuarial system and the related influences on modern financial industry. From the perspective of the basic relation of finance and economy, the financial in the role and influence on the economy growing at the same time presents a sense of core independence. With the gradual refinement of modern financial department and the division of labor, the increasingly rich trading tools and functions of the increasingly diverse, financial activities have been penetrated into every corner of daily life, big to the national construction, small to the food and clothing live line, everything is inseparable from financial support, the combination of financial and economic more and more close, especially for a role in promoting the economic development of the financial development has been confirmed that a large number of empirical research institute. Our research proposes the novel paradigm for the related challenges that will be meaningful for further development and optimization of the relate areas.

\section{References}

[1] Paudel, Y., et al. "Risk allocation in a public - private catastrophe insurance system: an actuarial analysis of deductibles, stop - loss, and premiums." Journal of Flood Risk Management 8.2 (2015): 116-134.

[2] Mitchell, Olivia S., Raimond Maurer, and J. Michael Orszag. "Retirement System Risk Management: Implications of the New Regulatory Order." (2016).

[3] Nomura, Akiko. "Success of Government Growth Strategy Holds Key to Sustainability of Japan's Public Pension System--Implications from 2014 Actuarial Valuation Results." Nomura Journal of Capital Markets 6.2 (2014).

[4] Jinping, X. I. A. O. "Hallow on Significance of Maternity Insurance Actuarial and Characteristics of the System in our Country." International Business and Management 11.1 (2015): 41-45.

[5] Guo-zhu, Tuo, and Zhu Jun-sheng. "Several Issues to be Solved for Improving on the Agricultural Insurance System in China." Insurance Studies 2 (2014): 006. 